\title{
PENGARUH SUPERVISI DAN INTEGRITAS TERHADAP KINERJA GURU SD NEGERI SE-KECAMATAN SALO KABUPATEN KAMPAR
}

\author{
Lusi Susanti ${ }^{1)}$ \\ Rr. Sri Kartikowati ${ }^{2)}$ \\ Makhdalena ${ }^{3)}$ \\ 1) Post Graduate Student of Riau University \\ 2) Lecturer of Education Management Study Programme PPs University of Riau \\ 3) Lecturer of Education Management Study Programme PPs University of Riau
}

\begin{abstract}
This study aims to analyze the effect of Supervision and Integrity to Teachers' performance at Elementary School in Salo District Kampar Regency. The population is a primary school teachers' of Salo Districts in totalling of 150 respondents; the sample is set by proportionate stratifield random sampling technique, to obtain 109 respondents. The data is collected by distributing questionnaire to the variables of supervision and integrity; while for teachers' performance variable is collected through documentation. Data were analyzed using multiple regression. The result showed: (1) a positive effect of Supervision to Teachers' performance; (2) a positive effect of Integrity to Teachers' performance; and (3) a positive effect of Supervision and Integrity together to Teachers' performance. The study concluded there are positive effect and significant of Supervision and Integrity together to Teachers' performance at Elementary School in Salo District Kampar Regency.
\end{abstract}

Keywords : Supervision, Integrity, Teachers' Performance 


\title{
PENGARUH SUPERVISI DAN INTEGRITAS TERHADAP KINERJA GURU SD NEGERI SE-KECAMATAN SALO KABUPATEN KAMPAR
}

\begin{abstract}
ABSTRAK
Penelitian ini bertujuan untuk menganalisis pengaruh Supervisi dan Integritas terhadap Kinerja Guru SD Negeri se-Kecamatan Salo Kabupaten Kampar. Populasi penelitian adalah guru SD Negeri se-Kecamatan Salo yang berjumlah 150 responden, kemudian sampel ditetapkan dengan teknik propotionate stratifield random sampling, sehingga diperoleh 109 responden. Cara pengumpulan data dilakukan dengan penyebaran angket untuk variabel supervisi dan integritas, sedangkan untuk variabel kinerja guru dengan dokumentasi. Data dianalisis dengan menggunakan regresi berganda. Hasil studi menunjukkan bahwa: (1) terdapat pengaruh positif antara supervisi terhadap kinerja guru; (2) terdapat pengaruh positif antara integritas terhadap kinerja guru; dan (3) terdapat pengaruh positif antara supervisi dan integritas secara bersama-sama terhadap kinerja guru. Kesimpulan penelitian bahwa terdapat pengaruh yang positif dan signifikan antara Supervisi dan Integritas secara bersama-sama terhadap Kinerja Guru SD Negeri se-Kecamatan Salo Kabupaten Kampar.
\end{abstract}

Kata Kunci: Supervisi; Integritas; Kinerja Guru

\section{PENDAHULUAN}

Guru merupakan sumber daya manusia yang sangat menentukan keberhasilan proses belajar mengajar di sekolah, oleh karena itu guru diharapkan mempunyai kinerja yang baik agar menghasilkan peserta didik yang berkualitas. Kualitas pendidikan yang baik akan mewarnai intelektualitas dan kemajuan suatu bangsa, lebih-lebih pada era globalisasi yang penuh dengan persaingan. Itulah sebabnya pendidikan senantiasa memerlukan upaya perbaikan dan peningkatan sejalan dengan semakin tingginya kebutuhan dan tuntutan kehidupan masyarakat yang mendambakan sosok yang berkepribadian.

Guru yang berkepribadian baik akan memiliki kinerja yang baik dan secara sadar penuh tanggung jawab berusaha melaksanakan segala tugas yang diberikan kepadanya dengan baik sesuai dengan kemampuan yang dimilikinya untuk mendapatkan hasil kerja yang maksimal. Sebaliknya apabila seorang guru tidak mempunyai kinerja yang baik hanya akan memberikan dampak negatif bagi guru itu sendiri maupun sekolah tempat ia bekerja. Guru dituntut memiliki kinerja yang mampu memberikan dan merealisasikan harapan dan keinginan semua pihak terutama masyarakat umum yang telah mempercayai sekolah dan guru dalam membina anak didik. Kinerja merupakan faktor penting untuk mendukung keberhasilan suatu pekerjaan seseorang baik dalam kapasitas pribadi maupun sebagai seorang guru. Banyak akibat yang tidak menguntungkan bagi organisasi atau sekolah disebabkan oleh kinerja yang rendah.

Kinerja yang masih rendah dapat dilihat dari fenomena-fenomena yang terlihat pada SD Negeri se-Kecamatan Salo yaitu guru-guru masih menggunakan metode ceramah dalam 
mengajar sehingga peserta didik merasa jenuh dan bosan dengan penjelasan guru, dalam mengajar guru belum mengacu pada RPP, bahkan perangkat pembelajaran dibuat setelah mengajar. Sebagai guru seharusnya mempersiapkan RPP terlebih dahulu sebelum mengajar di kelas, karena mengajar berdasarkan urutan kegiatan pembelajaran yang ada dalam RPP akan terasa lebih mudah, masih ada guru yang menggunakan alat peraga yang tradisional dan tidak sesuai dengan perkembangan zaman. Hali ini menandakan bahwa guru tersebut tidak kreatif dan inovatif dalam menciptakan suasana belajar yang menyenangkan.

Fenomena selanjutnya yaitu kurangnya etos kerja yang dimiliki oleh guru, dan kurangnya tanggung jawab dalam menjalankan tugasnya seperti kurang disiplin dalam ketepatan waktu datang ke sekolah. Rendahnya kedisiplinan dalam tugas sebagai guru tentu berkaitan dengan kinerja guru. Dari fenomena-fenomena tersebut dapat dilihat bahwa kinerja guru di SD Negeri se-Kecamatan Salo masih rendah.

Kinerja seorang guru dapat dilihat dari menjalankan profesinya sebagai guru terutama dalam melaksanakan perencanaan, sebagai pendidik dan pengajar, penempatan penggunaan metode-metode pengajaran untuk perbaikan secara terus menerus. Hasibuan (2007) mengemukakan bahwa "kinerja adalah suatu hasil kerja yang dicapai seseorang dalam melaksanakan tugas-tugas yang dibebankan kepadanya yang didasarkan atas kecakapan, pengalaman, dan kesungguhan serta waktu" Hal ini mengisyaratkan bahwa kinerja guru dapat diartikan sebagai hasil yang dicapai oleh guru atas pelaksanaan tugas profesional dan fungsionalnya dalam pembelajaran yang telah ditentukan dalam kurun waktu tertentu.
Kinerja guru dapat dipengaruhi beberapa faktor, diantaranya adalah supervisi dan integritas. Hal ini sejalan dengan pendapat Dale Timple dalam Sarita (2012) terdapat dua faktor yang mempengaruhi kinerja yaitu faktor internal dan faktor eksternal. Faktor internal adalah faktor-faktor yang berhubungan dengan sifat-sifat seseorang meliputi sikap, sifat kepribadian, integritas, sifat fisik, motivasi, umur, jenis kelamin, pendidikan, pengalaman kinerja, latar belakang budaya, dan variabel personal lainnya. Faktor eksternal adalah faktorfaktor yang mempengaruhi kinerja yang berasal dari lingkungan meliputi kebijakan organisasi, kepemimpinan, tindakan-tindakan rekan kerja, supervisi pengawasan, sistem upah, dan lingkungan sosial.

Seorang guru harus memiliki kinerja yang tinggi agar mampu mengajar dengan penuh antusias, kegembiraan dan penuh gairah sehingga menimbulkan daya tarik tersendiri bagi murid-muridnya. Guru yang memiliki kinerja yang tinggi tentu memiliki daya kreativitas dan inisiatif yang tinggi pula dalam memperbaiki kegiatan-kegiatan kependidikan. Dalam mencapai kinerja maka diperlukan supervisi dan integritas. Peterson dalam Suhardan (2010) mengatakan bahwa supervisi merupakan observasi yang langsung terhadap kegiatan pekerjaan utama yang kemudian ditindaklanjuti dengan pemberian umpan balik yang positif berupa perbaikan. Dari pengertian tersebut maka supervisi dapat diartikan sebagai pembinaan yang dilakukan oleh kepala sekolah untuk membantu para guru dan pegawai sekolah lainnya dalam melakukan pekerjaan mereka secara efektif dan permasalahan yang ada dalam kegiatan belajar mengajar. Apabila supervisi yang dilakukan 
kepala sekolah baik, maka kinerja guru tersebut akan meningkat.

Selain supervisi, guru juga harus memiliki integritas yang baik. Integritas menurut Cooper dan Sawaf (2002) adalah kepatuhan terhadap prinsip-prinsip moral dan etika, kedalaman watak moral, kejujuran. Integritas juga didefinisikan sebagai keadaan yang menyeluruh, penuh, utuh. Integritas juga merupakan keselarasan antara niat, pikiran, perkataan dan perbuatan. Niat dan pikiran tentunya merupakan aspek pribadi yang tidak nampak, sulit dirasakan dan diukur. Sedangkan perkataan dan perbuatan adalah aspek yang nampak, dapat dirasakan dan dievaluasi. Memiliki keselarasan niat, pikiran, perkataan dan perbuatan baik dan benar merupakan petunjuk dari keutuhan pribadi dan sikap yang konsisten. Perbuatan atau tindakan yang diselaraskan tersebut adalah perbuatan yang baik dan benar yang sesuai dengan nilai-nilai institusi/lembaga, masyarakat, serta memenuhi prinsip-prinsip tata kelola yang baik.
Apabila integritas seorang guru baik akan mencerminkan yang baik pula dan segala tugas yang dibebankan kepadanya akan dilaksanakan dengan sebaik-baiknya. Dengan demikian Supervisi dan Integritas dapat mempengaruhi Kinerja Guru.

Tujuan penelitian ini adalah untuk melakukan pengujian hipotesis penelitian pengaruh Supervisi dan Integritas terhadap Kinerja Guru SD Negeri se-Kecamatan Salo Kabupaten Kampar.

\section{METODOLOGI PENELITIAN}

Pendekatan penelitian ini menggunakan pendekatan kuantitatif deskriptif dengan metode survei. Penelitian ini dilaksanakan di SD Negeri se-Kecamatan Salo Kabupaten Kampar. Waktu penelitian dilakukan selama 10 bulan mulai bulan Oktober 2014 sampai dengan bulan Juli 2015.

Variabel-variabel yang diteliti dapat dilihat pada model konstelasi pengaruh antar variabel pada Gambar 1 .

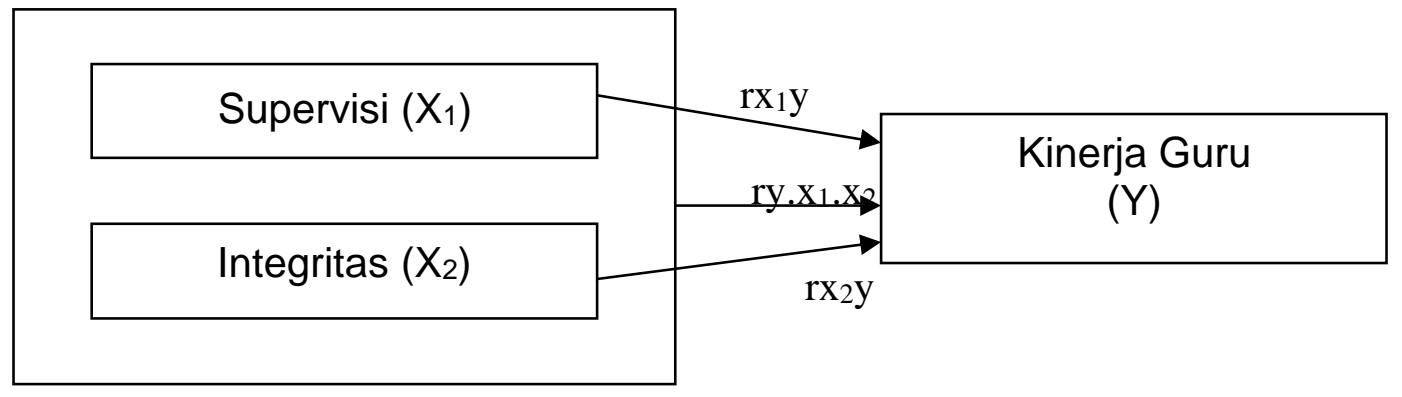

\section{Gambar 1. Konstelasi Pengaruh antar Variabel}

Data untuk variabel supervisi dan integritas dikumpulkan dengan melakukan penyebaran angket yang dikembangkan sendiri oleh penulis, sedangkan untuk variabel kinerja guru dengan dokumentasi data diperoleh melalui analisis dokumentasi mencakup Peraturan Menteri Pendidikan Nasional
No. 35 Tahun 2010 tentang Petunjuk Teknis Pelaksanaan Jabatan Fungsional Guru dan Angka Kreditnya.

Populasi penelitian adalah seluruh guru Pegawai Negeri Sipil (PNS) SD Negeri Kecamatan Salo Kabupaten Kampar, berjumlah 150 orang, kemudian sampel ditetapkan 
dengan teknik propotionate stratifield random sampling, sehingga diperoleh responden sebanyak 109 orang.

Pengumpulan data dalam penelitian ini menggunakan angket yang berisikan pernyataan-pernyataan tentang supervisi dan integritas. Angket yang telah disediakan menggunakan empat alternatif pilihan jawan yaitu: (1) Selalu, (2) Sering, (3) Jarang, (4) Tidak Pernah. Sedangkan Kinerja guru diambil dari nilai PKG dokumentasi kepala sekolah. Data selanjutnya dianalisis dengan menggunakan uji normalitas, uji

Tabel 1. Koefisien Regresi Berganda Supervisi dan Integritas terhadap Kinerja Guru

\section{Coefficients $^{\text {a }}$}

\begin{tabular}{|c|c|c|c|c|c|c|}
\hline \multirow{2}{*}{\multicolumn{2}{|c|}{ Model }} & \multicolumn{2}{|c|}{$\begin{array}{c}\text { Unstandardized } \\
\text { Coefficients }\end{array}$} & \multirow{2}{*}{$\begin{array}{c}\begin{array}{c}\text { Standardize } \\
\text { d } \\
\text { Coefficients }\end{array} \\
\text { Beta } \\
\end{array}$} & \multirow{2}{*}{$\mathrm{t}$} & \multirow[b]{2}{*}{ Sig. } \\
\hline & & $\mathrm{B}$ & Std. Error & & & \\
\hline \multirow[t]{3}{*}{1} & (Constant) & 27.934 & 5.115 & & 5.461 & .000 \\
\hline & Supervisi & .208 & .052 & .364 & 4.034 & .000 \\
\hline & Integritas & .033 & .036 & .083 & .917 & .001 \\
\hline
\end{tabular}

a. Dependent Variable: Kinerja_Guru

Dari tabel 1, Supervisi $\left(\mathrm{X}_{1}\right)$ dan Integritas $\left(\mathrm{X}_{2}\right)$ secara bersama-sama terhadap Kinerja Guru (Y) dapat disusun regresi yaitu:

$$
\begin{aligned}
& \hat{\mathbf{Y}}=\mathbf{a}+\mathrm{b}_{1} \mathrm{X}_{1}+\mathrm{b}_{2} \mathrm{X}_{2} \\
& \hat{\mathbf{Y}}=\mathbf{2 7 , 9 3 4}+\mathbf{0 , 3 6 4} \mathrm{X}_{1}+\mathbf{0 , 0 8 3} \mathrm{X}_{2}
\end{aligned}
$$

Interpretasi dari regresi di atas adalah sebagai berikut:

a. Konstanta (a) $=27,934$ artinya jika Supervisi dan Integritas di obyek penelitian sama dengan nol (0), maka Kinerja Guru (Y) sebesar 27,934.

b. Koefisien regresi $\left(b_{1}\right)=0,364$ dan bertanda positif, artinya jika variabel Supervisi naik satu satuan, maka terjadi peningkatan terhadap Kinerja Guru (Y) sebesar 0,364 (variabel Kinerja Guru naik sebesar $0,364)$. homogenitas, uji linieritas dan regresi berganda dengan bantuan program Statistical Product and Service Solution (SPSS) versi 17.

\section{HASIL PENELITIAN DAN PEMBAHASAN}

Berdasarkan hasil perhitungan diperoleh persamaan regresi berganda yang menyatakan pengaruh antara supervisi dan integritas terhadap kinerja guru yang ditunjukkan pada tabel 1 . 
sebesar 0,364. Selanjutnya pengaruh variabel supervisi terhadap kinerja guru menghasilkan nilai $13,2 \%$. Artinya supervisi memberi kontribusi yang signifikan terhadap kinerja guru sebesar $13,2 \%$. Kontribusi ini dalam kategori sangat rendah.

Hasil penelitian ini sejalan dengan pendapat Suharsimi dan Hadiyanto dalam Fetrianis (2013) bahwa supervisi adalah melakukan pembinaan kepada sekolah pada umumnya dan guru pada khususnya agar kualitas pembelajarannya meningkat dan agar mereka berkembang kemampuannya secara optimal.

Hasil penelitian ini juga sesuai dengan penelitian yang dilakukan oleh Badrudin (2014) dengan judul Pengaruh Supervisi dan Motivasi Kerja terhadap Kinerja Guru pada MTs Negeri Anyar Kabupaten Serang Propinsi Banten. Hasil penelitian menunjukkan bahwa terdapat pengaruh yang signifikan dan positif antara supervisi terhadap kinerja guru.

Jika kualitas supervisi meningkat, maka akan mempengaruhi peningkatan kinerja guru.

\section{Pengaruh Integritas $\left(X_{2}\right)$ terhadap Kinerja Guru (Y)}

Hasil penelitian menunjukkan bahwa integritas memiliki pengaruh yang signifikan dengan arah positif terhadap kinerja guru di SD Negeri seKecamatan Salo Kabupaten Kampar. Hal ini ditunjukkan dengan koefisien regresi integritas terhadap kinerja guru 0,083 . Maksudnya adalah jika variabel integritas naik satu satuan, maka terjadi peningkatan terhadap kinerja guru sebesar 0,083 . Selanjutnya pengaruh variabel integritas terhadap kinerja guru menghasilkan nilai $0,69 \%$. Artinya integritas memberi kontribusi yang signifikan terhadap kinerja guru sebesar
0,69\%. Kontribusi ini dalam kategori sangat rendah.

Hal ini sejalan dengan pemikiran Thomas Suyatno (2012) yang menyatakan bahwa bersikap jujur tanpa memandang keadaan dan tempat menunjukkan kepatuhan terhadap nilainilai kejujuran, kemudian harus mempunyai konsistensi yang menunjukkan apa yang dia katakan dan apa yang dia lakukan adalah sama.

Hasil penelitian ini juga sesuai dengan pendapat Antonius (2014) bahwa integritas mendorong pencapaian hasil yang baik berupa kinerja baik atau pencapaian hal-hal baik dalam kehidupan.

Hasil penelitian ini sesuai dengan penelitian yang dilakukan oleh Jonter Hutapea (2007) dengan judul Hubungan Kepemimpinan Spiritual dan Integritas Institusional Guru dengan Prestasi Kerja Guru SMP Negeri di Kecamatan Siborongborong. Hasil penelitian menunjukkan adanya hubungan yang signifikan dengan arah positif antara integritas institusional guru dengan prestasi kerja guru. Semakin tinggi integritas institusional guru, maka semakin tinggi pula prestasi kerja guru.

Guru yang memiliki integritas yang tinggi dalam bekerja akan lebih mudah mengelola suasana bekerja yang menyenangkan, sehingga dapat meningkatkan kinerja guru yang lebih baik.

\section{Pengaruh Supervisi $\left(X_{1}\right)$ dan Integritas $\left(\mathrm{X}_{2}\right)$ terhadap Kinerja Guru $(Y)$ \\ Hasil penelitian menunjukkan} bahwa supervisi dan integritas secara bersama-sama memiliki pengaruh yang signifikan dengan arah positif terhadap kinerja guru SD Negeri se-Kecamatan Salo Kabupaten Kampar dengan besar pengaruh 14,3\%. Hasil penelitian tersebut menunjukkan bahwa variabel 
supervisi dan integritas memberikan kontribusi yang lemah terhadap kinerja guru SD Negeri se-Kecamatan Salo Kabupaten Kampar.

Hasil penelitian ini sejalan dengan penelitian yang dilakukan I Made Suarna dan kawan-kawan (2013) dengan judul Determinasi Kepemimpinan Kepala Sekolah, Supervisi Akademik dan Sikap Guru terhadap Profesinya dengan Kinerja Guru SD Negeri Gugus II di Kecamatan Melaya, Kabupaten Jembrana. Hasilnya menunjukkan bahwa antara kepemimpinan kepala sekolah, supervisi akademik, dan sikap guru terhadap Profesinya berpengaruh terhadap kinerja guru.

Dari hasil penelitian ini menunjukkan bahwa supervisi dan integritas dianggap kurang efektif untuk meningkatkan kinerja guru. Hal ini dikarenakan kontribusi yang dihasilkan lemah. Oleh sebab itu, untuk meningkatkan kinerja guru dapat dicari variabel lain yang lebih baik kontribusinya.

\section{SIMPULAN DAN SARAN}

1. Simpulan

Dari hasil penelitian ini maka diperoleh kesimpulan sebagai berikut:

a. Supervisi berpengaruh positif dan signifikan terhadap Kinerja Guru di SD Negeri se-Kecamatan Salo Kabupaten Kampar. Supervisi memberikan kontribusi yang signifikan terhadap kinerja guru sebesar 13,2\%. Kontribusi ini dalam kategori sangat rendah, untuk itu diperlukan upaya untuk memperbaiki dan meningkatkan supervisi guna meningkatkan kinerja guru. Upaya-upaya yang dilakukan antara lain: 1) Guru harus memiliki persepsi yang positif terhadap supervisi yang dilakukan oleh atasan di sekolah;
2) Guru harus mengetahui seberapa pentingnya supervisi dalam organisasi sekolah dan proses belajar mengajar di sekolah.

b. Integritas berpengaruh positif dan signifikan terhadap Kinerja Guru di SD Negeri se-Kecamatan Salo Kabupaten Kampar. Integritas memberikan kontribusi yang signifikan terhadap kinerja guru sebesar 0,69\%. Kontribusi ini dalam kategori sangat rendah, untuk itu diperlukan upaya untuk meningkatkan integritas guru guna meningkatkan kinerja guru. Upaya-upaya yang dilakukan antara lain: 1) Guru harus memiliki inovasi dan juga harus memiliki orientasi kepada hasil; 2) Guru harus memiliki orientasi kepada seluruh masyarakat yang ada di dalam organisasi; dan 3) Guru harus senantiasa memiliki keyakinan dalam diri dalam menjalankan tugas yang di emban agar berhasil.

c. Supervisi dan Integritas secara bersama-sama berpengaruh positif dan signifikan terhadap Kinerja Guru di SD Negeri seKecamatan Salo Kabupaten Kampar. Besar pengaruh supervisi dan integritas terhadap kinerja guru memberikan kontribusi sebesar 14,3\%. Untuk itu harus ada upaya meningkatkan supervisi. dan integritas terhadap kinerja guru. Kinerja guru dapat ditingkatkan dengan membekali diri tentang ilmu pengetahuan yang berkaitan dengan meningkatkan kemampuan dalam mencapai kinerja yang lebih baik.

2. Saran

Berdasarkan kesimpulan, maka saran yang akan diberikan adalah: 
a. Bagi Kepala Sekolah diharapkan setelah mengetahui bahwa supervisi untuk guru sangat dibutuhkan dalam peningkatan kinerja guru.

b. Tindak lanjutnya kepada para guru disarankan agar selalu bekerja sama dengan kepala sekolah, melaksanakan tugas sesuai dengan program sekolah sehingga tujuan dapat tercapai dengan baik melalui kinerja yang efektif.

c. Guru diharapkan memperbanyak pelatihan-pelatihan khusus mengenai cara meningkatkan kinerja dengan cara menggiatkan kegiatan yang dapat meningkatkan kinerja.

d. Seorang Kepala Sekolah harus memberikan supervisi yang baik kepada para guru. Sebagai seorang inovator, kepala sekolah harus memiliki strategi tepat untuk menjalin hubungan harmonis dengan lingkungan, mencari gagasan, mengintegrasikan kegiatan, memberikan teladan dan mengembangkan model pembelajaran inovatif.

\section{DAFTAR PUSTAKA}

Atoshoki Gea, Antonius. (2014). Integritas Personal dan Kepemimpinan Etis. Jurnal Humaniora, Vol. 5, No. 2.

Badrudin. (2014). Pengaruh Supervisi dan Motivasi Kerja terhadap Kinerja Guru pada MTs Negeri Anyar Kabupaten Serang Propinsi Banten. Jurnal Reformasi Administrasi, Vol. 1, No. 1
Cooper, Robert K dan Anyman Sawaf. (2002). Executive EQ; Emotional Intelligence in Leadership and Organization, alih Bahasa Alex Tri Kancono Widodo. Jakarta: Gramedia Pustaka Utama.

Fetrianis. (2013). Persepsi Guru tentang Pelaksanaan Supervisi Pembelajaran oleh Kepala Sekolah di SMP Negeri Kecamatan Lareh Sago Halaban Kabupaten Lima Puluh Kota. Jurnal

Hasibuan, Malayu. (2007). Manajemen Sumber Daya Manusia. Jakarta: Bumi Aksara.

Hutapea, Jonter. (2007). Hubungan Kepemimpinan Spiritual dan Integritas Institusional Guru dengan Prestasi Kerja guru SMP Negeri di Kecamatan Siborongborong. Medan: Tesis Pascasarjana Universitas Negeri Medan.

Peraturan Menteri Pendidikan Nasional No. 35 Tahun 2010 tentang Petunjuk Teknis Pelaksanaan Jabatan Fungsional Guru dan Angka Kreditnya.

Sarita Permata. (2012). Pengaruh Pengendalian Internal dan Gaya Kepemimpinan terhadap Kinerja Karyawan SPBU Yogyakarta. Jurnal Nominal. Vol. 1, Nomor 1

Suarna, I Made, dan kawan-kawan. (2013). Determinasi Kepemimpinan Kepala Sekolah, Supervisi Akademik dan Sikap Guru terhadap Profesinya 
dengan Kinerja Guru SD Negeri Gugus II di Kecamatan Melaya, Kabupaten Jembrana. E-Journal Program Pascasarjana Universitas Pendidikan Ganesha, Volume 3.
Suhardan, Dadang. (2010). Supervisi Profesional. Bandung: Alfabeta.

Suyatno, Thomas. (2012). Faktor-faktor Penentu Kualitas Pendidikan Sekolah Menengah Umum di Jakarta. Jurnal. 